\title{
Formation and Dissociation of Complex between Alkaline Protease Inhibitor (API-2c) and Subtilisin $\mathrm{BPN}^{\prime \dagger}$
}

\author{
Keitarou Suzuki, Masaru Uyeda and Motoo Shibata \\ Laboratory of Medicinal Microbiology, Faculty of Pharmaceutical Sciences, \\ Kumamoto University, Kumamoto 862, Japan
}

Received March 6, 1980

\begin{abstract}
API-2c, one of the alkaline protease inhibitors produced by Streptomyces griseoincarnatus strain No. KTo-250, interacts with subtilisin BPN'. The API-2c-subtilisin BPN' complex was isolated by gel filtration on Sephadex G-100. Its homogeneity was determined by disc electrophoresis. From the results of molecular weight determination of the complex (MW 86,000) and of inhibitory assay of the API-2c released from the complex, it was shown that the complex was composed of one mole (two subunits) of API-2c and two moles of subtilisin BPN'.

The inhibitory activity was gradually released from the complex by dialysis against $0.05 \mathrm{~N} \mathrm{HCl}$ at $4{ }^{\circ} \mathrm{C}$. The inhibitor released showed a different mobility from virgin API-2c. These results suggest that API-2c was modified to API-2c* which peptide linkage in the reactive site was specifically cleaved.
\end{abstract}

In the previous papers, ${ }^{1,2)}$ we reported that a strain (KTo-250) of Streptomyces griseoincarnatus produced three kinds of protease inhibitors designated as API-2a, API-2b and API-2c in the culture filtrate. Purification procedures and some properties of API- $2 b$ and API- $2 c$ have also been described. The strain produced API-2b $\rightarrow$ API-2c converting protease $^{3)}$ and API-2 degrading protease ${ }^{4)}$ which were thought to be concerned in the fate of API-2 in the growing system. Purification procedures and some properties of these enzymes have also been described.

In the present paper, the interaction of API$2 \mathrm{c}$ with subtilisin $\mathrm{BPN}^{\prime}$ was examined, and formation and dissociation of the complex between API-2c and subtilisin BPN' are $^{\prime}$ mainly described.

\section{MATERIALS AND METHODS}

Materials. API-2c used in this work was prepared from the culture filtrate of Streptomyces griseoincarnatus strain No. KTo-250 as described in the previous paper. ${ }^{2)}$ Its homogeneity was determined by disc electrophoresis.

+ Studies on Alkaline Protease Inhibitor (API-2) Produced by Streptomyces griseoincarnatus Strain No. KTo-250. Part V. For Parts $I \sim I V$, see refs. $1 \sim 4$.
Subtilisin BPN ${ }^{\prime}$ (Nagase Biochemicals, Ltd.), Sephadex G-100 (Pharmacia Fine Chemicals), sodium laurylsulfate, acrylamide, $N, N^{\prime}$-methylenebisacrylamide and $N, N, N$ ', $N$-tetramethylenediamine (these four reagents from Nakarai Chemicals, Ltd.) were purchased from the respective companies.

Determination of protein concentration. The concentrations of API-2c and substilisin BPN' were determined with a Hitachi 124 spectrophotometer taking the extinction coefficients as $E_{1 \mathrm{~cm} .280 \mathrm{~nm}}^{1 \%}=8.7$ and 11.7 , respectively.

Polyacrylamide gel disc electrophoresis. Polyacrylamide gel disc electrophoresis was carried out according to the method of Davis ${ }^{51}$ at pH 8.0 using a $7 \%$ gel. Sodium dodecyl sulfate (SDS)-polyacrylamide gel disc electrophoresis was performed using a $14.5 \%$ gel. Samples were incubated, before electrophoresis, at room temperature for $24 \mathrm{hr}$ in $0.01 \mathrm{M}$ phosphate buffer ( $\mathrm{pH} \mathrm{7.2)} \mathrm{containing}$ $1 \%$ SDS in the presence of 2-mercaptoethanol. The gels were stained with $0.2 \%$ Coomassie brilliant blue R-250 in methanol-acetic acid-water $(5: 1: 5, \mathrm{v} / \mathrm{v})$, and destained with $7.5 \%$ acetic acid in $5 \%$ methanol.

Assay for the inhibitory activity. Assay procedure for the inhibitory activity was the same as that described in the previous paper. ${ }^{11}$ Other methods were also the same as those described in the previous papers. ${ }^{|-4|}$ 


\section{RESULTS AND DISCUSSION}

Molecular weight determination of $A P I-2 c$

The molecular weight of API-2c in its native state was estimated by gel filtration on Sephadex G-100 as about $32,000 .{ }^{2)}$ To determine the molecular weight of its subunit, SDSpolyacrylamide gel disc electrophoresis was performed at $7 \mathrm{~mA}$ per gel column for $6 \mathrm{hr}$ at room temperature in $0.1 \mathrm{M}$ phosphate buffer ( $\mathrm{pH} 7.2$ ) containing $0.1 \%$ SDS. In Fig. 1, relative mobilities were plotted against the logarithm of molecular weight for each reference protein and API-2c. From the results, an approximate molecular weight of 11,000 was obtained for the subunit of API-2c. This value was virtually the same as the minimal molecular weight calculated from the amino acid composition. ${ }^{2)}$

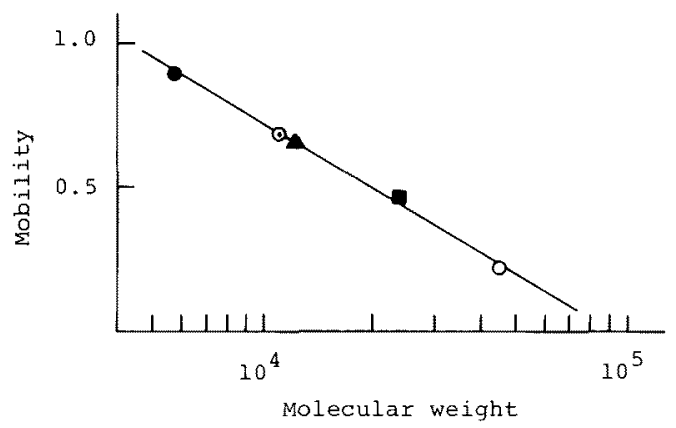

FIG. 1. Molecular Weight Determination of API-2c by SDS-Polyacrylamide Gel Disc Electrophoresis.

- insulin (MW 5,730); $\boldsymbol{\Delta}$, cytochrome $c$ (MW 12,400);

D, trypsin (MW 24,000); O, ovalbumin (MW 46,000); C, API-2c

Determination of inhibitory equivalent of $A P I-$ $2 c$ to subtilisin $B P N^{\prime}$

Inhibitory equivalent of API-2c to subtilisin $\mathrm{BPN}^{\prime}$ was determined by measuring enzyme inhibition at various inhibitor concentrations.

API-2c was dissolved in $0.01 \mathrm{~m}$ boric acidborax buffer ( $\mathrm{pH} \mathrm{9.0)}$. One $\mathrm{ml}$ of each solution was mixed with $1 \mathrm{ml}$ of a subtilisin BPN' solution containing $10.7 \mu \mathrm{g}$. After preincubation for $5 \mathrm{~min}$ at $37^{\circ} \mathrm{C}$, each $1 \mathrm{ml}$ of $2 \%$ casein and $0.2 \mathrm{M}$ borax- $\mathrm{NaOH}$ buffer ( $\mathrm{pH} 9.5$ ) was added. After incubation for $15 \mathrm{~min}$, the

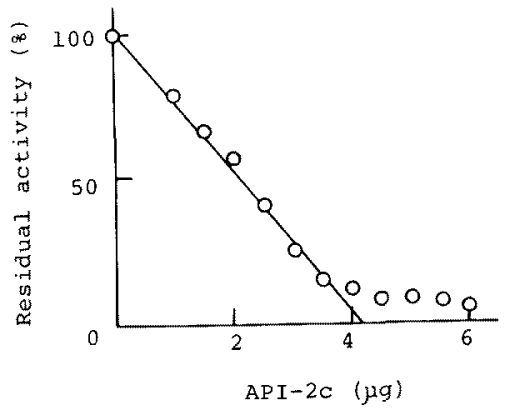

FIG. 2. Determination of Inhibitory Equivalent of API-2c to Subtilisin BPN'.

See the text for experimental details.

residual proteolytic activity was determined. For these experiments, crystalline subtilisin BPN' was dialyzed against distilled water to be free from the denatured enzyme before use. As shown in Fig. 2, $1 \mu \mathrm{g}$ of API-2c inhibited $2.6 \mu \mathrm{g}$ of the enzyme. Thus, considering the molecular weights of API-2c subunit (MW 11,000) and subtilisin BPN' (MW 27,700), one subunit of API-2c inhibits one molecule of the enzyme.

\section{Isolation of API-2c-subtilisin BPN' complex}

API-2c $(5 \mathrm{mg})$ was dissolved in $0.02 \mathrm{M}$ boric acid-borax buffer ( $\mathrm{pH} 7.5$ ) containing $0.1 \mathrm{M}$ $\mathrm{KCl}$. To this solution was added an enzyme solution containing $20 \mathrm{mg}$ of subtilisin BPN in the same buffer. The reaction mixture was allowed to stand for $1 \mathrm{hr}$ at $37^{\circ} \mathrm{C}$, and then applied to a Sephadex G-100 column previously equilibrated with $0.02 \mathrm{M}$ boric acidborax buffer ( $\mathrm{pH} 7.5$ ) containing $0.1 \mathrm{M} \mathrm{KCl}$. The column was eluted with the same buffer. Figure 3 shows the elution pattern. The main peak showed almost neither proteolytic activity nor inhibitory activity. Even after being heated in a boiling water bath for $10 \mathrm{~min}$, the main peak showed little inhibitory activity. However, after treatment with $0.05 \mathrm{~N} \mathrm{HCl}$, as described in the subsequent section, the peak recovered almost all the original inhibitory activity. Thus, the main peak was regarded as to contain an API-2c-subtilisin BPN' complex. Fractions corresponding to the main peak were pooled and added solid ammonium sulfate to $80 \%$ saturation. After standing 


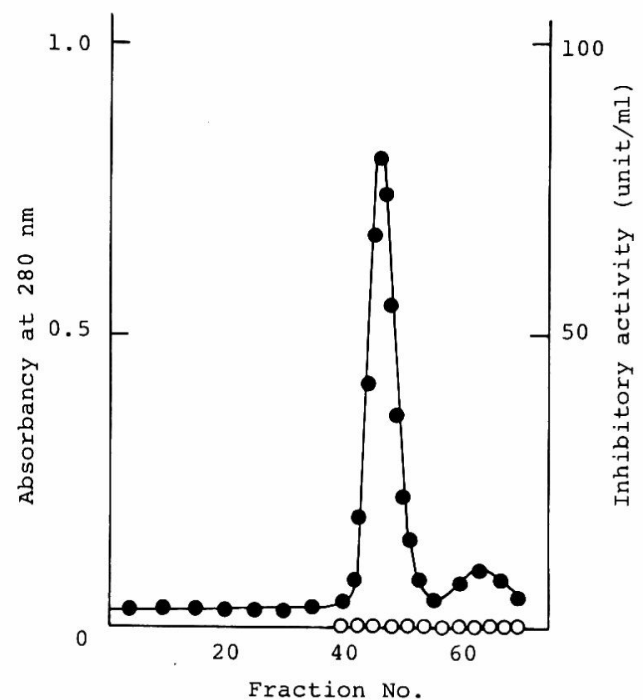

FIG. 3. Gel Filtration of the Reaction Mixture of API2c and Subtilisin BPN' on Sephadex G-100.

Buffer, $0.02 \mathrm{M}$ boric acid-borax buffer ( $\mathrm{pH} 7.5$ ) containing $0.1 \mathrm{M} \mathrm{KCl}$; flow rate, $10 \mathrm{ml} / \mathrm{hr}$; column size, $1.8 \times 105$ $\mathrm{cm}$; fraction size, $3 \mathrm{ml}$. Amounts of enzyme and inhibitor were $20 \mathrm{mg}$ and $5 \mathrm{mg}$, respectively.

- - absorbancy at $280 \mathrm{~nm}$; $\bigcirc-\bigcirc$, inhibitory activity.

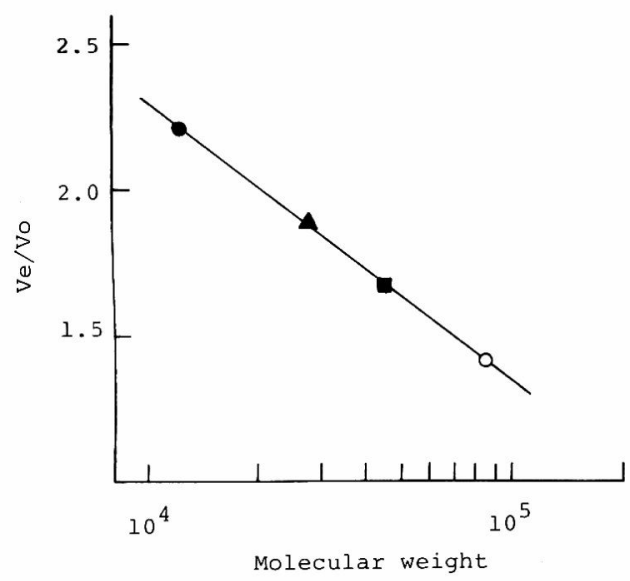

FIG. 5. Molecular Weight Determination of API-2cSubtilisin BPN' Complex on Sephadex G-100 Column.

- cytochrome $c$ (MW 12,400); $\boldsymbol{\Delta}$, AP-I (MW 27,500);

D, ovalbumin (MW 46,000); $\bigcirc$, the complex.

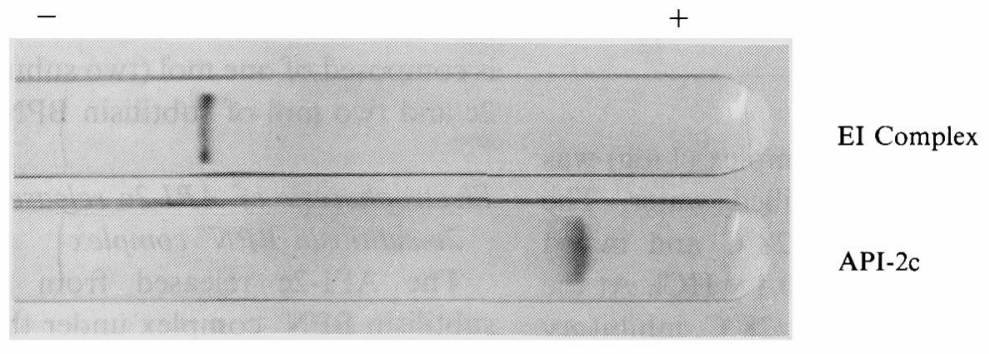

FIG. 4. Polyacrylamide Gel Disc Electrophoresis of API-2c and API-2c-Subtilisin BPN' Complex.

overnight at $4^{\circ} \mathrm{C}$, the precipitate was collected by centrifugation, dissolved in a minimal volume of distilled water, and dialyzed against water to remove any salt, and then lyophilized.

Homogeneity of the lyophilized API-2csubtilisin BPN $^{\prime}$ complex was examined by polyacrylamide gel disc electrophoresis. As shown in Fig. 4, the complex migrated as a single, clear band.

Molecular weight of API-2c-subtilisin BPN' complex

The molecular weight of the API-2c- subtilisin $\mathrm{BPN}$ ' complex was estimated according to the method of Andrews ${ }^{6)}$ with a Sephadex G-100 column. Gel filtration was carried out at $4^{\circ} \mathrm{C}$ in $0.02 \mathrm{M}$ boric acid-borax buffer ( $\mathrm{pH} 7.5$ ) containing $0.1 \mathrm{M} \mathrm{KCl}$. In Fig. 5, the ratio of elution volume to void volume is plotted against the logarithm of molecular weight for each reference protein and the complex. From the results, an approximate molecular weight of 86,000 was obtained for the complex. It was thus suggested that the complex was composed of two mol of subtilisin $\mathrm{BPN}^{\prime}$ and one mol (two subunits) of 
API-2c.

\section{Dissociation of API-2c-subtilisin BPN complex}

To find the best conditions for dissociation of the API-2c-subtilisin BPN' complex, it was treated under various conditions. One half $\mathrm{ml}$ of the complex solution was incubated at various temperatures, and then mixed with $0.5 \mathrm{ml}$ of $0.1 \mathrm{~N} \mathrm{HCl}$. After neutralization with $1 \mathrm{ml}$ of $0.2 \mathrm{M}$ borax- $\mathrm{NaOH}$ buffer ( $\mathrm{pH} 9.5$ ), inhibitory activity was assayed. As Table I shows, more API-2c was released from the complex with $0.05 \mathrm{~N} \mathrm{HCl}$ at $28^{\circ} \mathrm{C}$ than at other temperatures examined.

Table I. Dissociation of API-2cSubtilisin BPN' CoMPLeX

\begin{tabular}{lrrrc}
\hline & $\begin{array}{c}\text { Temp. } \\
\left({ }^{\circ} \mathrm{C}\right)\end{array}$ & $\mathrm{pH}$ & $\begin{array}{c}\text { Time } \\
(\mathrm{min})\end{array}$ & $\begin{array}{c}\text { Recovery of } \\
\text { inhibitory } \\
\text { activity } \\
(\%)\end{array}$ \\
\hline $0.05 \mathrm{~N} \mathrm{HCl}$ & 0 & 1.5 & 60 & 85 \\
$0.05 \mathrm{~N} \mathrm{HCl}$ & 21 & 1.5 & 60 & 85 \\
$0.05 \mathrm{~N} \mathrm{HCl}$ & 28 & 1.5 & 60 & 94 \\
$0.05 \mathrm{~N} \mathrm{HCl}$ & 37 & 1.5 & 60 & 58 \\
No HCl & 100 & 7.5 & 10 & 12 \\
\hline
\end{tabular}

API-2c-subtilisin BPN' complex (1 mg) was dissolved in $0.5 \mathrm{ml}$ of distilled water. The solution was incubated at $28^{\circ} \mathrm{C}$ and mixed with $0.5 \mathrm{ml}$ of preincubated $0.1 \mathrm{~N} \mathrm{HCl}$. At the indicated incubation times at $28^{\circ} \mathrm{C}$, inhibitory activity of the mixture was assayed after neutralization. As shown in Fig. 6, dis-

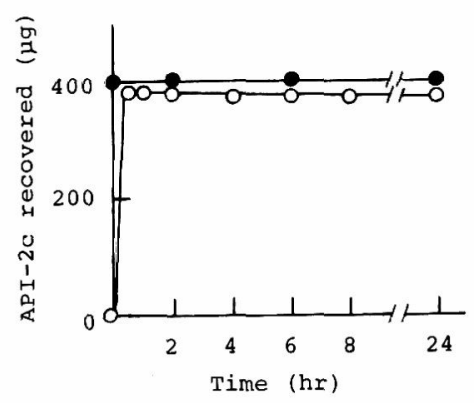

FIG. 6. Release of API-2c from the Complex in $0.05 \mathrm{~N}$ $\mathrm{HCl}$ at $28^{\circ} \mathrm{C}$.

One half $\mathrm{ml}$ of the aqueous complex solution was mixed with $0.5 \mathrm{ml}$ of $0.1 \mathrm{~N} \mathrm{HCl}$ and incubated at $28^{\circ} \mathrm{C}$ for indicated period of time. Then $1 \mathrm{ml}$ of $0.2 \mathrm{M}$ borax$\mathrm{NaOH}$ buffer ( $\mathrm{pH} 9.5$ ) was added to the reaction mixture and the quantity of API-2c released from the complex was assayed by inhibitory activity.

$\mathrm{O}-\mathrm{O}, 1,000 \mu \mathrm{g}$ of the complex; - $400 \mu \mathrm{g}$ of API2c (control).

sociation completed within $30 \mathrm{~min}$, and $385 \mu \mathrm{g}\left(1.2 \times 10^{-8} \mathrm{~mol}\right)$ of API- $2 \mathrm{c}$ was released from $1,000 \mu \mathrm{g}$ of the complex. If the remainder is regarded as subtilisin $\mathrm{BPN}^{\prime}$, it amounted to $615 \mu \mathrm{g}\left(2.2 \times 10^{-8} \mathrm{~mol}\right)$. These results support the view that API-2c-subtilisin BPN' complex is composed of one mol (two subunits) of API$2 \mathrm{c}$ and two mol of subtilisin BPN'.

Electrophoresis of API-2c released from API$2 c$-subtilisin $B P N^{\prime}$ complex

The API-2c released from the API-2csubtilisin BPN' complex under the conditions described above was compared with virgin API-2c by polyacrylamide gel disc electro-

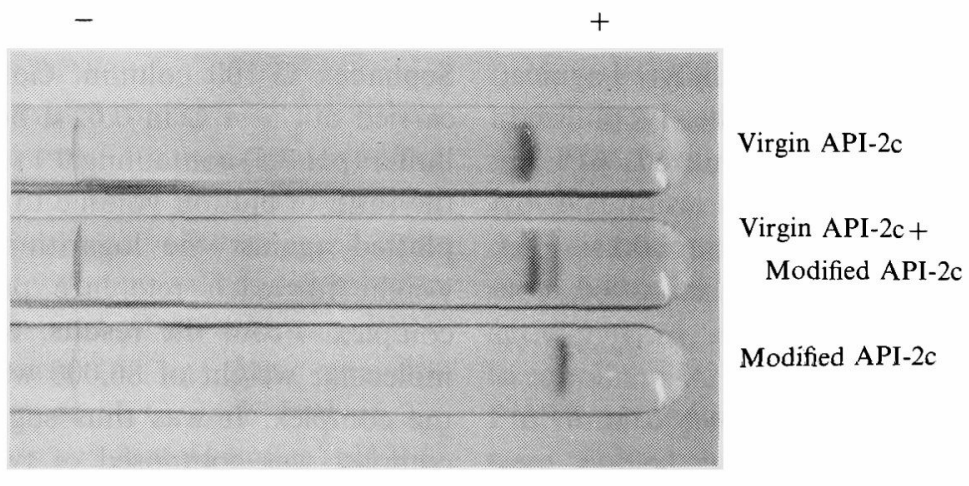

FIG. 7. Polyacrylamide Gel Disc Electrophoresis of Virgin and Modified API-2c at pH 8.0. 
phoresis. In every case, they showed the same mobility. The API- $2 c$ gradually released from the complex by dialysis against $0.05 \mathrm{~N} \mathrm{HCl}$ at $4^{\circ} \mathrm{C}$, however, showed a different mobility from that of virgin API-2c, as shown in Fig. 7. It is thought that API-2c is modified by specific cleavage of peptide linkage in its reactive site. ${ }^{7)}$

We will described in detail on this modification and the reactive site of API-2c in the next paper. ${ }^{8)}$

\section{REFERENCES}

1) M. Uyeda, K. Suzuki, H. Uwatoko and M. Shibata, Agric. Biol. Chem., 42, 49 (1978).

2) K. Suzuki, M. Uyeda and M. Shibata, ibid., 42, 1539 (1978).

3) M. Uyeda, K. Suzuki, M. Sugiyama and M. Shibata, ibid., 43, 1849 (1979).

4) K. Suzuki, M. Uyeda, M. Sugiyama and M. Shibata, ibid., 44, 113 (1980).

5) B. J. Davis, Ann. N.Y. Acad. Sci., 121, 404 (1964).

6) P. Andrews, Biochem. J., 96, 595 (1965).

7) M. Uyeda and K. Suzuki, Agric. Biol. Chem., 44, 699 (1980).

8) K. Suzuki, M. Uyeda, K. Ookubo and M. Shibata, ibid., 44, 2555 (1980). 